\title{
Site use and connectivity of female grey seals (Halichoerus grypus) around Wales
}

\author{
Izzy Langley ${ }^{1}$ (D) Tobias Rosas da Costa Oliver ${ }^{1,2} \cdot$ Lex Hiby $^{3} \cdot$ Thomas B. Stringell $^{2} \cdot$ Ceri W. Morris $^{2}$. \\ Oliver O'Cadhla ${ }^{4}$ Lisa Morgan ${ }^{5} \cdot$ Kate Lock $^{6} \cdot$ Sarah Perry $^{7}$. Stephen Westcott ${ }^{2} \cdot$ Dave Boyle $^{8} \cdot$ Birgitta I. Büche $^{8}$. \\ Edward M. Stubbings ${ }^{8} \cdot$ Rebecca M. Boys $^{2} \cdot$ Holly Self $^{2} \cdot$ Charlie Lindenbaum $^{2} \cdot$ Powell Strong $^{9} \cdot$ Mick Baines $^{10}$. \\ Patrick P. Pomeroy ${ }^{1}$
}

Received: 11 November 2019 / Accepted: 27 April 2020 / Published online: 30 May 2020

(c) The Author(s) 2020

\begin{abstract}
Grey seals (Halichoerus grypus) are a qualifying feature of three special areas of conservation (SACs) in Wales, yet relatively little is known of their site use along this coastline. Since 1992, many individuals and organisations have contributed to a grey seal photographic identification database held by Natural Resources Wales, which is one of the largest and oldest of its kind, providing key information from grey seal haul-out sites around the Celtic and Irish Seas. Here, we investigated spatial connectivity of haul-out sites and fidelity of adult females to breeding sites. The minimum number of adult female grey seals using the area between 1992 and 2016 was 2688. Individual capture histories and relative spatial transition probabilities $\left(P_{i j}\right)$ between pairs of location groups were calculated. Adjacent locations were highly connected (e.g. Lleyn Peninsula and Bardsey, $\left.P_{i j}=0.7\right)$ but connections spanned the entire region, up to $230 \mathrm{~km}$ apart (e.g. Skomer and Dee Estuary, $\left.P_{i j}=0.004\right)$. Resights were recorded within SACs (e.g. Lleyn Peninsula and Bardsey [Lleyn Peninsula and the Sarnau SAC], $P_{i j}=0.7$ ), between SACs (e.g. Bardsey and Skomer [Pembrokeshire Marine], $P_{i j}=0.03$ ), between SACs and non-designated areas (e.g. Skerries and Bardsey, $\left.P_{i j}=0.09\right)$ and between sites outside any protected area (e.g. Dee Estuary and Anglesey, $P_{i j}=0.5$ ). While inter-annual fidelity to breeding sites was high $\left(P_{i j}=0.82-1\right)$, individual female grey seals moved throughout the region. This evidence of extensive site use beyond protected areas is important for the management and conservation of grey seals around Wales.
\end{abstract}

Responsible Editor: V. Paiva.

Reviewed by S. Sayer and an undisclosed expert

Electronic supplementary material The online version of this article (https://doi.org/10.1007/s00227-020-03697-8) contains supplementary material, which is available to authorized users.

Izzy Langley

i132@st-andrews.ac.uk

1 Sea Mammal Research Unit, Scottish Oceans Institute, University of St Andrews, St Andrews, Scotland, UK

2 Natural Resources Wales, Maes y Ffynnon, Bangor, Wales, UK

3 Conservation Research Ltd, Cambridge, England, UK

4 Marine Environment, Water Division, An Rionn TithíochtaPleanála Agus Rialtais Áitiúil, Cork, Republic of Ireland

5 RSPB Ramsey Island, St David's, Pembrokeshire, Wales, UK

\section{Introduction}

Population studies of long-lived animals must cover a substantial part of their lifespan, providing information on population size, status and vital rates, along with individual behaviour, to best inform management (Pianka 1970).

6 Natural Resources Wales, Martin's Haven, Pembrokeshire, Wales, UK

7 Cardigan Bay Marine Wildlife Centre, The Wildlife Trust of South and West Wales, New Quay, Wales, UK

8 The Wildlife Trust of South and West Wales, Skomer Island, C/O Lockley Lodge, Martin's Haven, Pembrokeshire, UK

9 Pembrokeshire College, Haverfordwest, Pembrokeshire, Wales, UK

10 Dyfed Wildlife Trust (Now The Wildlife Trust of South and West Wales), Bridgend, Wales, UK 
A significant challenge of marine spatial planning requires an understanding of how marine animals use their habitat and which areas are important throughout the animals' life history. Within recent decades, the UK population of grey seals (Halichoerus grypus) has undergone considerable changes in abundance and distribution, highlighting the need for continued monitoring at appropriate temporal and spatial scales (Boyd et al. 2006; SCOS 2018). Information on grey seals in Wales, where animals typically occupy difficult-to-survey locations, has accrued steadily, mainly through pup production monitoring (Baines et al. 1995; Westcott 2002; Westcott and Stringell 2003; Stringell et al. 2014).

Grey seals are long-lived top predators; females in the wild can reach ages in excess of 35 years (Pomeroy et al. 1999). In the UK, seals at well-studied colonies have high breeding site fidelity (Pomeroy et al. 1994, 2000) with a clockwise cline in mean birth date (from August in SW England to December in the southern North Sea; SCOS 2018). Breeding occurs in large remote colonies where each mother gives birth to a single pup which is nursed for around 18 days (Pomeroy et al. 1999). Seals spend much of the year foraging at sea, with foraging trips lasting 3-10 days (Thompson et al. 1991; McConnell et al. 1999; Russell et al. 2013). Grey seals haul-out onto land to rest, digest, breed and moult, and the number of animals at haul-out sites vary throughout the year (Baines et al. 1995; Sparling et al. 2007; Russell et al. 2015). Studies of movements of grey seals on the UK's east coast found that they spent $32 \%$ of their time travelling between haul-out sites (Thompson et al. 1991) and moved between haul-out sites up to 2,100 km apart (McConnell et al. 1999).

One third of the world's grey seals are associated with breeding sites in UK waters and recent estimates suggest that around 3\% of these 130,000 (age 1+) individuals use sites along the Welsh coastline (Thomas et al. 2019). Grey seals are listed in the EU Habitats Directive (Annex II of Council Directive 92/43/EEC on the conservation of natural habitats and of wild fauna and flora) and as a result, special areas of conservation (SACs) have been designated for the species. Three Welsh SACs have grey seals as a feature: Pembrokeshire Marine/Sir Benfro Forol, Cardigan Bay/Bae Ceredigion and Lleyn Peninsula and the Sarnau/Pen Llŷn a'r Sarnau.

EU Habitats Directive reporting requirements for SAC features have driven monitoring programmes to assess grey seal abundance, distribution and population parameters. Natural Resources Wales (NRW, formerly the Countryside Council for Wales, CCW) monitors the number of pups born in and around the grey seal associated SACs (Stringell et al. 2014). However, as evidence accumulates from elsewhere of animal movements beyond protected areas and across international boundaries (Vincent et al. 2017; Critchley et al. 2018; Sayer et al. 2019), it has become increasingly important to gain an understanding of how haul-out sites in the region are used and the connectivity between SACs and non-designated areas.

Information on individual behaviour as well as population parameters can be obtained from individual-based studies using capture-mark-recapture (CMR) techniques (Donovan et al. 1990). Often such studies required individual animals to be caught, anaesthetised, and artificially marked, either with a passive (brand, flipper tag) or active (telemetry tag) device of varying longevity (Fedak and Anderson 1982; Smout et al. 2011; Hiby et al. 2013). Building a representative marked sample of a population can be costly and time consuming and may be biased to those seals caught and handled. Handling wild animals also comes with associated risks to personnel and animals. A useful, non-invasive variation of CMR uses the subject's natural markings, including contrast between light/dark areas, patterning and scars, recognised in photographic images (photo-ID). Female grey seals have a stable pelage pattern from their earliest moulted coat through adulthood (Paterson et al. 2013), and the pattern legibility tends to be reinforced through adulthood with increased contrast between light and dark areas (Vincent et al. 2001). Pelage patterns from the same areas on the animals are compared in a quantitative and standardised process using semi-automated photo-ID software (ExtractCompare). This allows bulk processing of images which dramatically reduces the number of potential matches that require visual confirmation (Hiby and Lovell 1990; Hiby et al. 2013).

Whilst the number of grey seal pups born in Wales is monitored (Baines et al. 1995; Westcott 2002; Westcott and Stringell 2003; Stringell et al. 2014), very little in known of how seals use breeding and haul-out sites throughout the year, even for regions with protected status. This study provides the first detailed long-term analysis of the site-use and connections between grey seal breeding and haul-out sites along the Welsh coastline, using photo-ID data.

\section{Materials and methods}

\section{Data sources}

Photo-ID images and associated metadata from the Celtic and Irish Seas are stored in a custom database-EIRPHOT. Photo-ID images from 280 locations around Britain and Ireland were collected between 1992 and 2016, with a specific focus on the Celtic and Irish Seas since 1996 (Fig. 1). The EIRPHOT database was established in 1995 to investigate seasonal population size, inter-site movements and site fidelity at principal grey seal colonies in Ireland (Kiely et al. 2000) and was subsequently expanded to include photo-ID images and associated metadata from Wales, collected by CCW/NRW staff, students, trained volunteers and collaborating organisations. The database has developed into an 
Fig. 1 Celtic and Irish Sea grey seal haul-out sites covered by the EIRPHOT database. Sites are divided into location groups using natural boundaries, consistent with census reports (Baines et al. 1995). The 11 location groups in this study have two-letter codes and are distinguishable by colour: Anglesey, Bardsey, Ramsey, the Skerries, Skomer, Smalls and Grassholm (all islands in Wales); Angel Bay, Cardigan Bay, Lleyn Peninsula and North-West Pembrokeshire (all on mainland Wales); and the Dee Estuary (on the WalesEngland border). Sites on the Isle of Man and in Ireland are not included in this analysis

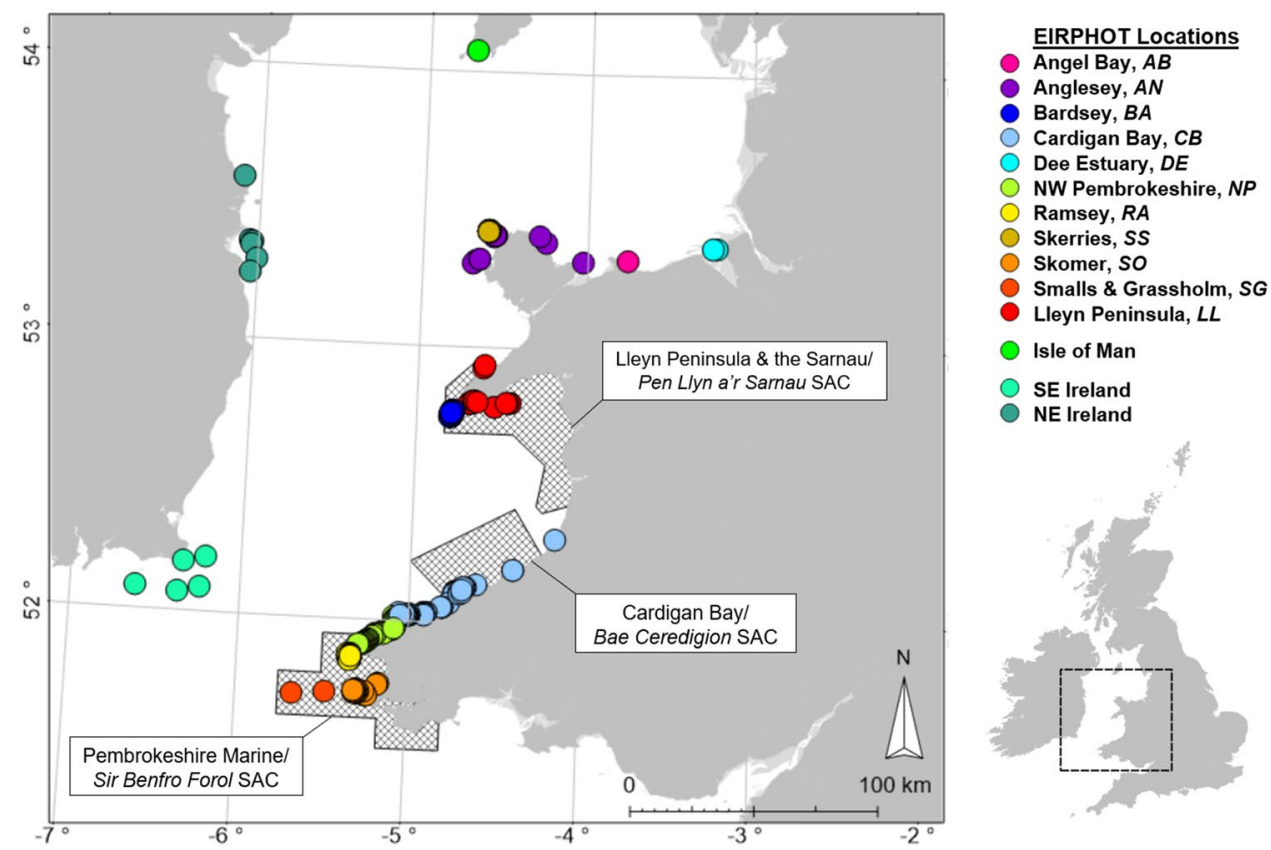

internationally important resource, containing over 17,000 photographic images of more than 9000 grey seals (Langley et al. 2018).

Images were collected at locations used by seals around the Welsh coast and islands $(n=246)$, with additional locations in eastern and western Ireland $(n=23)$, the Isle of Man $(n=3)$, England $(n=1)$ and France $(n=1)$. This study grouped haul-out locations by natural boundaries, consistent with census reports (Baines et al. 1995), producing 11 groups of locations around Wales (Fig. 1).

\section{Data preparation}

Here we consider only images of adult female grey seals, which are important in determining pup production. As an indicator of potential pup production, adult females have been the focus of historical surveys and represent $>95 \%$ of images in EIRPHOT, with the remaining images comprising males, juveniles, pups and "unknown", presumably taken opportunistically alongside female focussed surveys. Therefore, males were excluded from analysis, along with juveniles and pups ( $n$ [extracts] $=463$; see Supplementary Material 1, Table S1). The "unknown" and "blank" images, from seals whose age and sex were not recorded $(n=12,301)$, were assigned as adult females. Contributors to the database confirmed that "adult female" was the default age/ sex class, although this wasn't always recorded, but males, juveniles and pups had been consistently highlighted. To verify this, we inspected a selection of these "unknown/ blank" images and confirmed all were adult females. Typographical errors were corrected from the data entry stage (e.g. impossible dates for sampling occasions) and images of multiple individuals assigned in the field to the same ID were unmatched. Records in which metadata were conflicted and without any means of reconciliation were excluded from analysis ( $n=498$; see Langley et al. 2018 for further details).

\section{Data processing}

Pairwise comparisons of images were scored for similarity of standardised extracts using the open source, semiautomated pattern recognition software ExtractCompare, hereafter referred to as EC (https://conservationresearch.org. uk/Home/ExtractCompare). This software was originally developed for grey seals at the Sea Mammal Research Unit (SMRU; Hiby et al. 1990) and later extended in capability and functionality (Hiby et al. 2013). The area of the pelage used to compare across individuals is selected in relation to morphological features (nose, eyes, ears, flippers and pelvis) - software users are trained to be able to determine the location of hidden morphological features-and EC applies a three-dimensional, mathematical surface model to account for the orientation of the seal (Fig. 2). The pattern is extracted from the three-dimensional coordinates of the model, and the grey-scale intensities are scored numerically (see Hiby and Lovell 1990 for more details). Pairs of images are ranked by similarity of these scores. The top potential matches (exceeding a threshold similarity score of 0.75 ) are then visually confirmed or rejected by eye. This conservative approach, which ensures a low false rejection rate (failure to identify a true match), is a trade-off against processing time of large databases and the number of candidate matches which must be inspected visually (Hiby et al. 2013). 


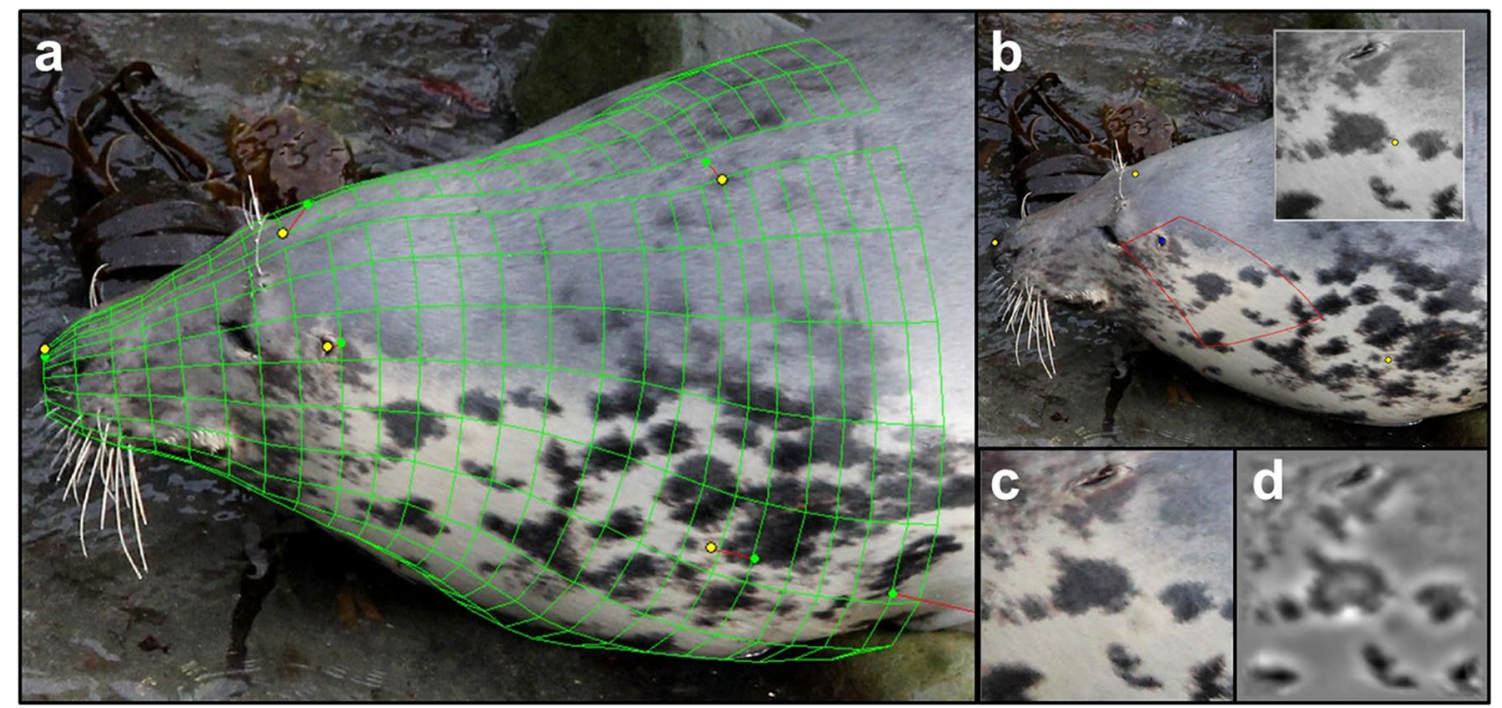

Fig. 2 Grey seal photographic identification data processing using the semi-automated pattern recognition software ExtractCompare (e.g. left head extract): a three-dimensional, mathematical surface model built from standard morphological reference points (yellow dots marking nose, ears and flippers [left, right, mid]); b pattern extract from three-dimensional coordinates (red box marking extractable area); c standardised pattern extract; d grey-scale intensities to be numerically scored and compared
EC allows for the use of extracted patterns from multiple sides and aspects (multi-biometric identification) which can reduce the likelihood of recognition error (Jain 2007). At present, if the images are available, ten different extracts may be used from a single grey seal, but these are unlikely to be independent. In the following analysis, we used images from a single aspect from a single side of a seal, using the most abundant aspect in the database (see below and Table S2: left head), reducing the likelihood of missed matches ("ghost" capture histories sensu Hiby et al. 2013). One way failures to match can occur if a pair of images from the same seal is from different aspects or sides and, therefore, cannot be matched unless additional information is available. Such images would appear erroneously in capture histories as two different seals.

\section{Data analysis}

The shortest, at-sea distance between each pair of location groups was calculated in GIS software (Manifold 8.0) by measuring the shortest path across a Boolean matrix with points $10 \mathrm{~km}$ apart. The shortest path between location group centres was calculated to the nearest $10 \mathrm{~km}$. The shortest, at-sea distance between capture and recapture locations was referred to as Rdist.

Custom written Spatially Explicit Capture-Recapture (SECR) software was used to create resighting records of individual seals at specified time intervals and identified by location. There were more identities available from head extracts within the database, in part because of a historical bias towards photographing heads of animals in the water, whereas in more recent years, the photographs taken also allowed neck extracts to be obtained. Photographs of the flanks, chests and abdomens are more difficult to obtain, particularly for seals in the water. We, therefore, concentrated our analyses on the extracts which were most numerous, over the longest period of time, in most locations. Preliminary data inspection found that "left heads" were the most numerous extracts overall in EIRPHOT (see Supplementary Material 1, Table S2); therefore, analyses were restricted to these.

An index of effort (i.e. the number of images collected) through time was variable across sites $\left(n_{\min }=62\right.$ at Angel Bay, $n_{\max }=3904$ at Bardsey Island; Fig. S1) and years $\left(n_{\min }=0\right.$ in 2000, $n_{\max }=2041$ in 2011). At some sites, surveys occurred multiple times within a given month while in others, a single survey might have occurred. In our analyses, the time step for sightings was set to calendar days to examine recaptures of any given individual seal at the highest resolution. The time step for sightings was set to calendar years to examine the wider temporal scale of resightings. For the remaining analyses, the capture interval was set to calendar month-in cases where more frequent surveys occurred, and multiple sightings were recorded for an individual within a month, only the first recorded location was used.

\section{Spatial connectivity of sites used between years}

Capture histories were produced for all uniquely identified adult female seals within the EIRPHOT database. For individuals seen more than once from left head extracts, the 
frequencies of recaptures between pairs of location groups were calculated. From these, relative spatial transition probability $(P)$ matrices were constructed between capture $(i)$ and recapture $(j)$ location groups. These represent the proportion of recaptures observed at location $j$ out of the total recaptures recorded originating at location $i$. We use terminology equivalent to assuming that the first capture location represents a seal's "origin" for operational purposes, i.e. a seal first identified at Skomer Island will be referred to as a Skomer seal. The proportion of recaptures occurring at the origin, as defined in this study, was termed the relative spatial identity transition probability $\left(P_{i j(\text { identity })}\right)$.

\section{Breeding site fidelity across years}

We examined spatial capture histories for individuals recorded at four known breeding areas during the months when most pupping occurs in Wales (beginning of August to end of November). The four breeding areas were: the Skerries, Bardsey Island, Ramsey Island and Skomer Island. Consecutive 4-year periods specific to each breeding area were used for analysis to represent each area's most data-rich consecutive years (see Supplementary Material 1, Fig. S2). In each year, the recapture window was set to the 4 months associated with breeding. Previous studies have shown that non-breeding females are rare in breeding areas and fidelity to breeding sites is high (Pomeroy et al. 1994). As pupping status of seals was not recorded in most cases, we assumed that the first location at which a female was recorded during this 4-month breeding season was her breeding location. This is a fair assumption as observations at breeding colonies show that females can arrive at their breeding location up to several weeks before pupping (Pomeroy et al. 2000; Morgan et al. 2018; Langley, pers. obs.).

For seals recorded at a breeding area within the breeding season, and recorded at least once again within the database, the frequency of recaptures between pairs of location groups were calculated from left head extracts. From these, relative spatial transition probability $(P)$ matrices were constructed between capture $(i)$ and recapture $(j)$ location groups across years, where $P_{i j \text { (identity) }}$ represented the observed probability of being resighted in the same location in consecutive years.

\section{Spatial connectivity of breeding and non-breeding areas within years}

The breeding site fidelity capture histories were used to generate relative spatial transition probability matrices between pairs of location groups where individuals were recaptured within the same year, inside and outside of the breeding season, over a 4-year period. The breeding season was again defined as August-November and the consecutive 4-year periods specific to each breeding area were again each area's most data-rich years.

\section{Results}

\section{EIRPHOT data}

The EIRPHOT database at time of publication contained 27,266 extracts in the library, from 16,737 images of adult female grey seals, across 2893 sampling occasions. From left head extracts, we estimate a minimum of 2688 individual adult female grey seals used haul-out sites around the Welsh coastline between 1992 and 2016. The number of uniquely identified individuals per year followed a bimodal distribution through time with peaks in 1997 and 2011 (Fig. 3).

\section{Captures and recaptures}

Capture histories, generated from 9281 left head extracts of 2688 individuals, were sensitive to the recapture interval considered. With the capture interval set to calendar years, 2219 seals $(83 \%)$ were never recaptured (photographed from same aspect) between 1992 and 2016 (see Supplementary Material 1, Table S3), and 469 individuals (17\%) were recaptured one or more times (Fig. 4).

With the recapture interval set to days (i.e. giving a maximum of 364 recaptures a year), the highest number of occasions when recaptures were recorded at surveyed sites between 1992 and 2016 was 28 - an individual seal was first recorded at the Lleyn Peninsula and subsequently recaptured at Anglesey, with 15 different capture records in 2010. With the recapture interval set to calendar years, this individual was recorded in five different years between 1992 and 2016: 2002, 2009, 2010, 2011 and 2012. The longest recorded capture history spanned 23 years, for a seal first recorded at Skomer, and recaptured in 11 years at either Skomer or Ramsey between 1992 and 2016.

\section{Spatial connectivity of sites used between years}

The at-sea distance between pairs of location groups (to the nearest $10 \mathrm{~km}$ ) ranged from 10 to $240 \mathrm{~km}$. Angel Bay and the Dee Estuary were the most isolated being greater than $10 \mathrm{~km}$ away from any other group, and the greatest at-sea distance of $240 \mathrm{~km}$ was between the Dee Estuary and the Smalls and Grassholm. The at-sea distance between capture and recapture locations (Rdist) averaged $50 \mathrm{~km}$ and the greatest Rdist was between Skomer and the Dee Estuary at $230 \mathrm{~km}$ (Table 1).

The highest between year relative spatial transition probability $\left(P_{i j}\right)$ for each location occurred within the same group (excluding Angel Bay and the Lleyn Peninsula; 


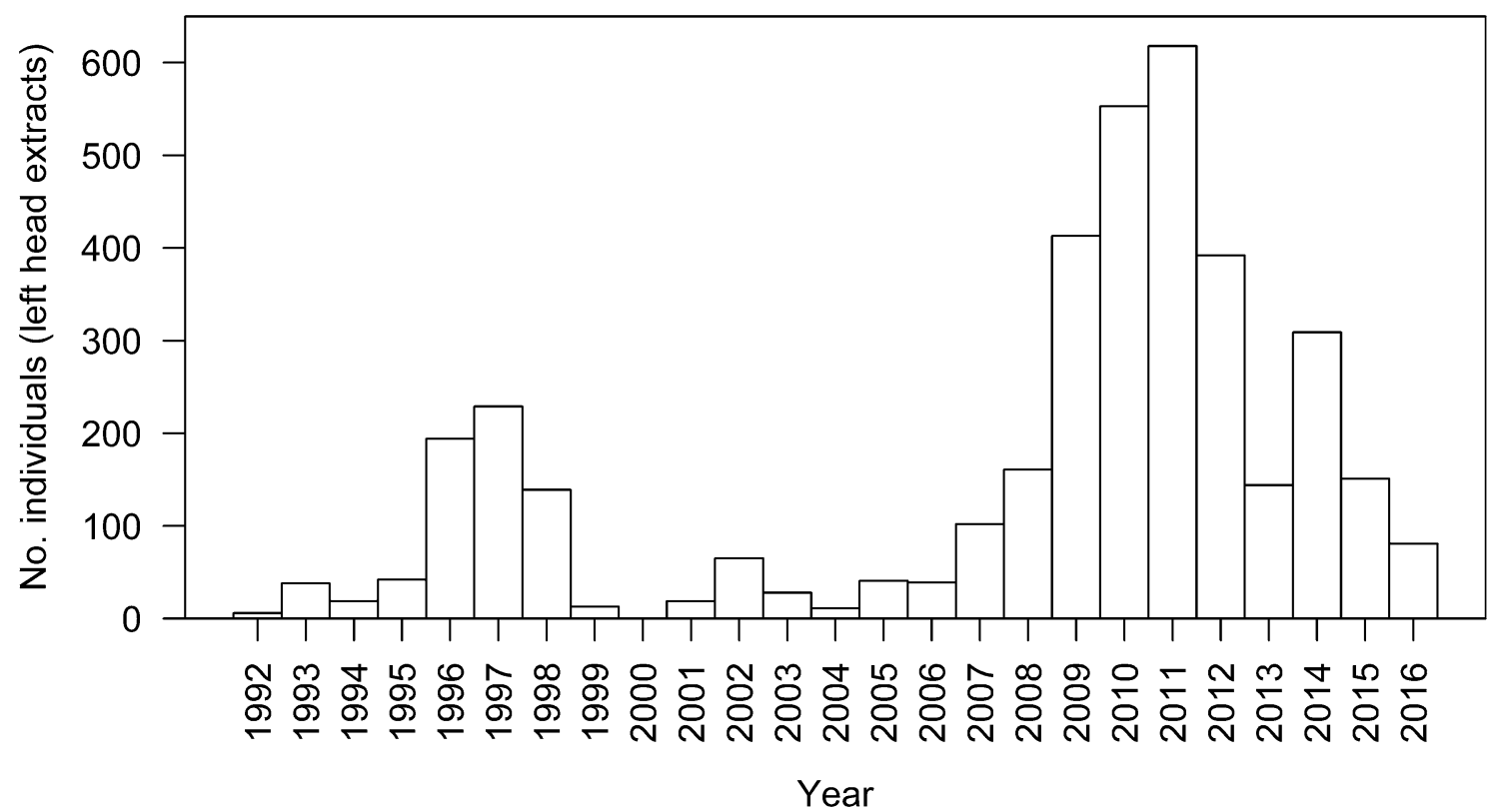

Fig. 3 Number of grey seals uniquely identified from photographs of left head extracts captured each year within the EIRPHOT database between 1992 and 2016

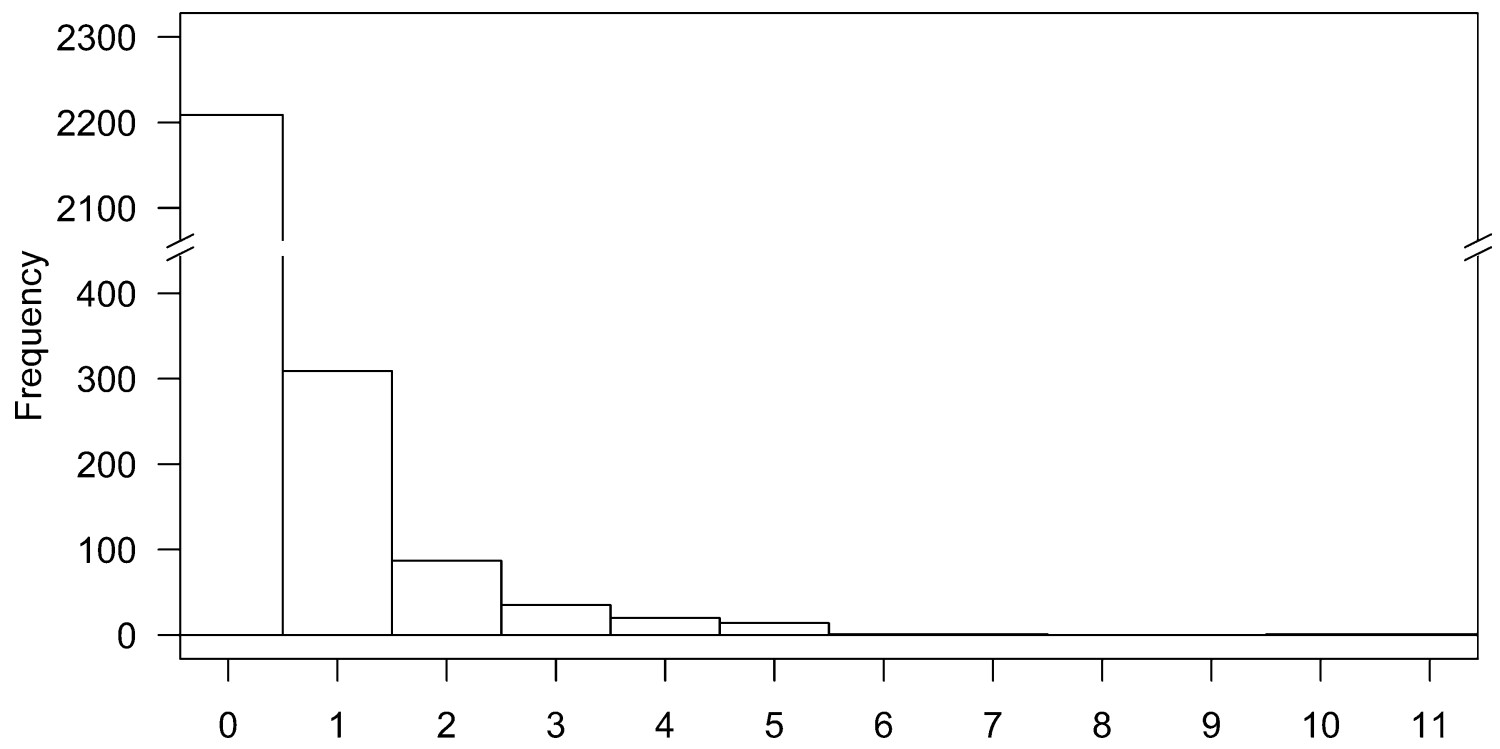

No. recaptures

Fig. 4 Recapture frequency (with a recapture interval of calendar years) for grey seals identified from photographs of left head extracts. Recaptures $=0$ represent the number of individuals captured/photographed once and not recaptured. $Y$-axis break from 440 to 2060 individuals

Table 1, Fig. 5) and the general trend across sites was that $P_{i j}$ decreased with distance (Fig. 6). Outliers to this trend were observed at the Dee Estuary, where seals were equally split between the Dee Estuary $\left(P_{i j}=0.5\right)$ and Anglesey $\left(P_{i j}=0.5\right)$, and at the Smalls \& Grassholm, where more seals were recaptured at Cardigan Bay $(40 \mathrm{~km}$ away, $\left.P_{i j}=0.2\right)$ than at Ramsey ( $\leq 10 \mathrm{~km}$ away, $\left.P_{i j}=0.08\right)$. Seals first recorded at the Lleyn Peninsula were the only seals that were most often recaptured outside of the same location (at Bardsey Island; $P_{i j}=0.7$ ). There were six seals in the database that were first recorded at Angel Bay, but none of these were subsequently recaptured anywhere else. 
Table 1 (a) Recapture frequencies, (b) spatial transition probabilities $\left(P_{i j(\text { identity })}\right.$ and $\left.P_{i j}\right)$ and (c) shortest at-sea distance to the nearest $10 \mathrm{~km}$, between capture $(i)$ and recapture $(j)$ location groups for adult female grey seals identified from left head extracts within the EIRPHOT database

\begin{tabular}{|c|c|c|c|c|c|c|c|c|c|c|c|c|c|}
\hline & \multirow{2}{*}{ (a) } & \multicolumn{11}{|c|}{ J } & \multirow{2}{*}{ Total } \\
\hline & & $\mathrm{AB}$ & \multirow{2}{*}{$\begin{array}{c}\mathrm{AN} \\
0\end{array}$} & \multirow{2}{*}{$\begin{array}{c}\text { BA } \\
0\end{array}$} & \multirow{2}{*}{$\begin{array}{c}\mathrm{CB} \\
0\end{array}$} & \multirow{2}{*}{$\begin{array}{c}\mathrm{DE} \\
0\end{array}$} & \multirow{2}{*}{$\begin{array}{c}\mathrm{LL} \\
0\end{array}$} & \multirow{2}{*}{$\begin{array}{c}\mathrm{NP} \\
0\end{array}$} & \multirow{2}{*}{$\begin{array}{c}\text { RA } \\
0\end{array}$} & \multirow{2}{*}{$\begin{array}{c}\text { SS } \\
0\end{array}$} & \multirow{2}{*}{$\begin{array}{c}\text { SO } \\
0\end{array}$} & \multirow{2}{*}{$\begin{array}{c}S G \\
0\end{array}$} & \\
\hline & $\mathrm{AB}$ & 0 & & & & & & & & & & & 0 \\
\hline \multirow{10}{*}{$i$} & AN & 0 & 41 & 4 & 0 & 5 & 0 & 2 & 1 & 12 & 0 & 0 & 65 \\
\hline & BA & 1 & 5 & 196 & 0 & 1 & 1 & 0 & 5 & 5 & 7 & 0 & 221 \\
\hline & CB & 0 & 1 & 4 & 29 & 0 & 1 & 11 & 2 & 1 & 0 & 1 & 50 \\
\hline & $\mathrm{DE}$ & 0 & 1 & 0 & 0 & 1 & 0 & 0 & 0 & 0 & 0 & 0 & 2 \\
\hline & $\mathrm{LL}$ & 0 & 1 & 6 & 0 & 0 & 0 & 0 & 0 & 1 & 1 & 0 & 9 \\
\hline & $\mathrm{NP}$ & 0 & 3 & 0 & 8 & 0 & 0 & 19 & 1 & 0 & 0 & 0 & 31 \\
\hline & RA & 0 & 0 & 3 & 0 & 0 & 0 & 2 & 41 & 1 & 5 & 0 & 52 \\
\hline & SS & 0 & 6 & 5 & 0 & 4 & 0 & 0 & 0 & 41 & 0 & 0 & 56 \\
\hline & SO & 0 & 0 & 6 & 0 & 1 & 0 & 0 & 26 & 1 & 219 & 1 & 254 \\
\hline & SG & 0 & 0 & 0 & 3 & 0 & 0 & 0 & 1 & 0 & 0 & 9 & 13 \\
\hline
\end{tabular}

\begin{tabular}{|c|l|}
\hline AB & Angel Bay \\
\hline AN & Anglesey \\
\hline BA & Bardsey \\
\hline CB & Cardigan Bay \\
\hline DE & Dee Estuary \\
\hline LL & Lleyn Peninsula \\
\hline NP & NW Pembrokeshire \\
\hline RA & Ramsey \\
\hline SS & Skerries \\
\hline SO & Skomer \\
\hline SG & Smalls \& Grassholm \\
\hline
\end{tabular}

\begin{tabular}{|c|c|c|c|c|c|c|c|c|c|c|c|c|}
\hline \multirow[t]{3}{*}{ (b) } & & \multicolumn{11}{|c|}{$i$} \\
\hline & & $\mathrm{AB}$ & AN & BA & CB & $\mathrm{DE}$ & LL & $\mathrm{NP}$ & RA & SS & $\mathrm{SO}$ & SG \\
\hline & $A B$ & 0 & 0 & 0 & 0 & 0 & 0 & 0 & 0 & 0 & 0 & 0 \\
\hline \multirow{10}{*}{$i$} & AN & 0 & 0.6 & 0.06 & 0 & 0.08 & 0 & 0.03 & 0.02 & 0.2 & 0 & 0 \\
\hline & BA & 0.005 & 0.02 & 0.9 & 0 & 0.005 & 0.005 & 0 & 0.02 & 0.02 & 0.03 & 0 \\
\hline & CB & 0 & 0.02 & 0.08 & 0.6 & 0 & 0.02 & 0.2 & 0.04 & 0.02 & 0 & 0.02 \\
\hline & $\mathrm{DE}$ & 0 & 0.5 & 0 & 0 & 0.5 & 0 & 0 & 0 & 0 & 0 & 0 \\
\hline & $\mathrm{LL}$ & 0 & 0.1 & 0.7 & 0 & 0 & 0 & 0 & 0 & 0.1 & 0.1 & 0 \\
\hline & $\mathrm{NP}$ & 0 & 0.1 & 0 & 0.3 & 0 & 0 & 0.6 & 0.03 & 0 & 0 & 0 \\
\hline & RA & 0 & 0 & 0.06 & 0 & 0 & 0 & 0.04 & 0.8 & 0.02 & 0.1 & 0 \\
\hline & SS & 0 & 0.1 & 0.09 & 0 & 0.07 & 0 & 0 & 0 & 0.7 & 0 & 0 \\
\hline & SO & 0 & 0 & 0.02 & 0 & 0.004 & 0 & 0 & 0.1 & 0.004 & 0.9 & 0.004 \\
\hline & SG & 0 & 0 & 0 & 0.2 & 0 & 0 & 0 & 0.08 & 0 & 0 & 0.6 \\
\hline
\end{tabular}

\begin{tabular}{|c|c|}
\hline & \multicolumn{1}{|c|}{$P_{i j}=0$} \\
\hline & $0<P_{i j}<0.2$ \\
\hline & $0.2 \leq P_{i j}<0.4$ \\
\hline & $0.4 \leq P_{i j}<0.6$ \\
\hline & $0.6 \leq P_{i j}<0.8$ \\
\hline & $0.8 \leq P_{i j} \leq 1$ \\
\hline
\end{tabular}

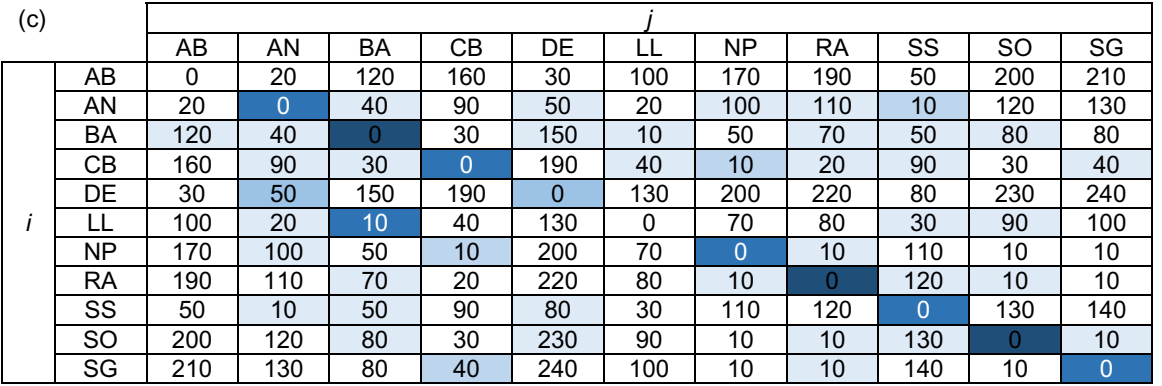

Angel Bay was only connected with one other location group: one seal out of 221 seen at Bardsey Island was recaptured at Angel Bay $\left(P_{i j}=0.005\right)$.

Seals first captured at Bardsey Island or in Cardigan Bay had recaptures in the greatest number of location groups. Bardsey seals were most often recaptured subsequently at Bardsey $\left(P_{i j}=0.9\right)$, but of those recaptured elsewhere, very few were within the same SAC at the Lleyn Peninsula $\left(P_{i j}=0.005\right)$. Most of the Bardsey seals recaptured elsewhere were at Skomer $\left(P_{i j}=0.03\right)$ and Ramsey $\left(P_{i j}=0.02\right)$, both of which are located within the Pembrokeshire Marine SAC. Bardsey seals were also recaptured in North Wales at Anglesey $\left(P_{i j}=0.02\right)$, Skerries $\left(P_{i j}=0.02\right)$, Angel Bay $\left(P_{i j}=0.005\right)$ and the Dee Estuary $\left(P_{i j}=0.005\right)$, which are all outside of any SAC. Similarly, Cardigan Bay seals were most often recaptured within Cardigan Bay $\left(P_{i j}=0.6\right)$, but also across many other location groups in both North and Southwest Wales: NW Pembrokeshire $\left(P_{i j}=0.2\right)$, Bardsey $\left(P_{i j}=0.08\right)$, Ramsey $\left(P_{i j}=0.04\right)$, and Anglesey, Lleyn Peninsula, Skerries and Smalls and Grassholm (all $\left.P_{i j}=0.02\right)$.

\section{Breeding site fidelity across years}

The consecutive 4-year period with the most data was selected for each breeding area (see Supplementary Material 1, Fig. S2). For the Skerries, this was 2009-2012 ( $n$ [sampling occasions] $=69)$, Bardsey Island was 2008-2011 $(n=384)$, Ramsey Island was 2013-2016 $(n=388)$ and Skomer Island was 2008-2011 $(n=790)$. The number of individuals identified during the breeding season over the 4-year period ranged from 152 in the Skerries to 500 at Bardsey Island. However, the proportion of these that were seen only once was similar across the four sites (mean \pm SD, $0.86 \pm 0.05$ ).

The relative spatial transition probabilities of female grey seals recorded within the same breeding area during the breeding season was high for all locations $\left(P_{i j \text { (identity })}=0.82\right.$, 0.97, 1, 0.89 at Skerries, Bardsey, Ramsey and Skomer, respectively; Table 2).

At Ramsey Island, no movement of individuals to other sites during the breeding season was detected. For individuals first captured in the Skerries, at Bardsey Island 

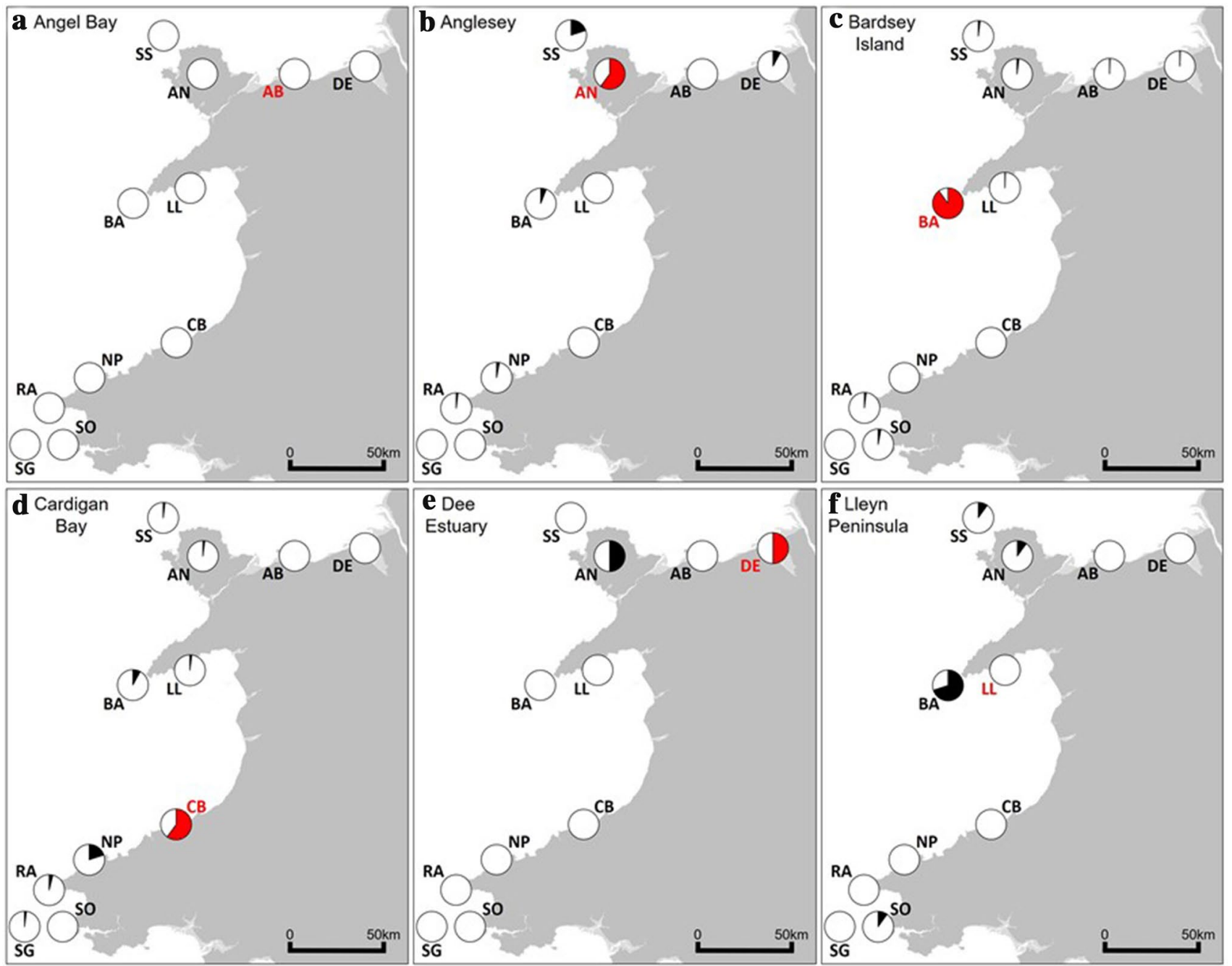

Fig. 5 Proportion of recaptures between pairs of grey seal haul-out location groups from long-term photo identification around Wales. Capture locations in each pairwise capture history are shown in red, recapture locations are shown in black

and Skomer Island, subsequent recaptures were recorded in other location groups. For Bardsey and Skomer, these were two other breeding sites (Skerries and Skomer for Bardsey, Bardsey and Ramsey for Skomer). However, for the Skerries, the highest number of recaptures outside of the Skerries was on Anglesey (a non-breeding site).

We also investigated the recapture frequency at the same and at different locations with varying recapture intervals (see Supplementary Material 1, Table S4). There was no obvious trend to suggest that site fidelity increased with time. With a recapture interval of 1 year (years 1-2, $2-3,3-4)$ and 3 years (1-4), the proportion of recaptures within the same location for each site was high $(0.75-1)$. With a recapture interval of 2 years $(1-3,2-4)$, there was a greater difference across sites with the Skerries having the lowest proportion of recaptures within the same location $(0.5)$.

\section{Spatial connectivity of breeding and non-breeding areas within years}

To investigate the relative spatial connectivity between breeding and non-breeding areas, we focussed on a consecutive 4-year period for each breeding site that spanned 2008-2016. There was no difference in the proportion of individuals only seen once for each year at each breeding site (see Supplementary Material 1, Table S5; $F=0.837$, $p>0.05)$.

Seals first captured at a breeding site within the breeding season were recaptured outside the season largely at the same location, but there were some recaptures at other locations (Table 3). Seals detected at the Skerries during the breeding season were recaptured in the same year at the Skerries $(n=6)$, Anglesey $(n=4)$ and Bardsey $(n=2)$. Bardsey seals were detected at Bardsey $(n=10)$, along with 


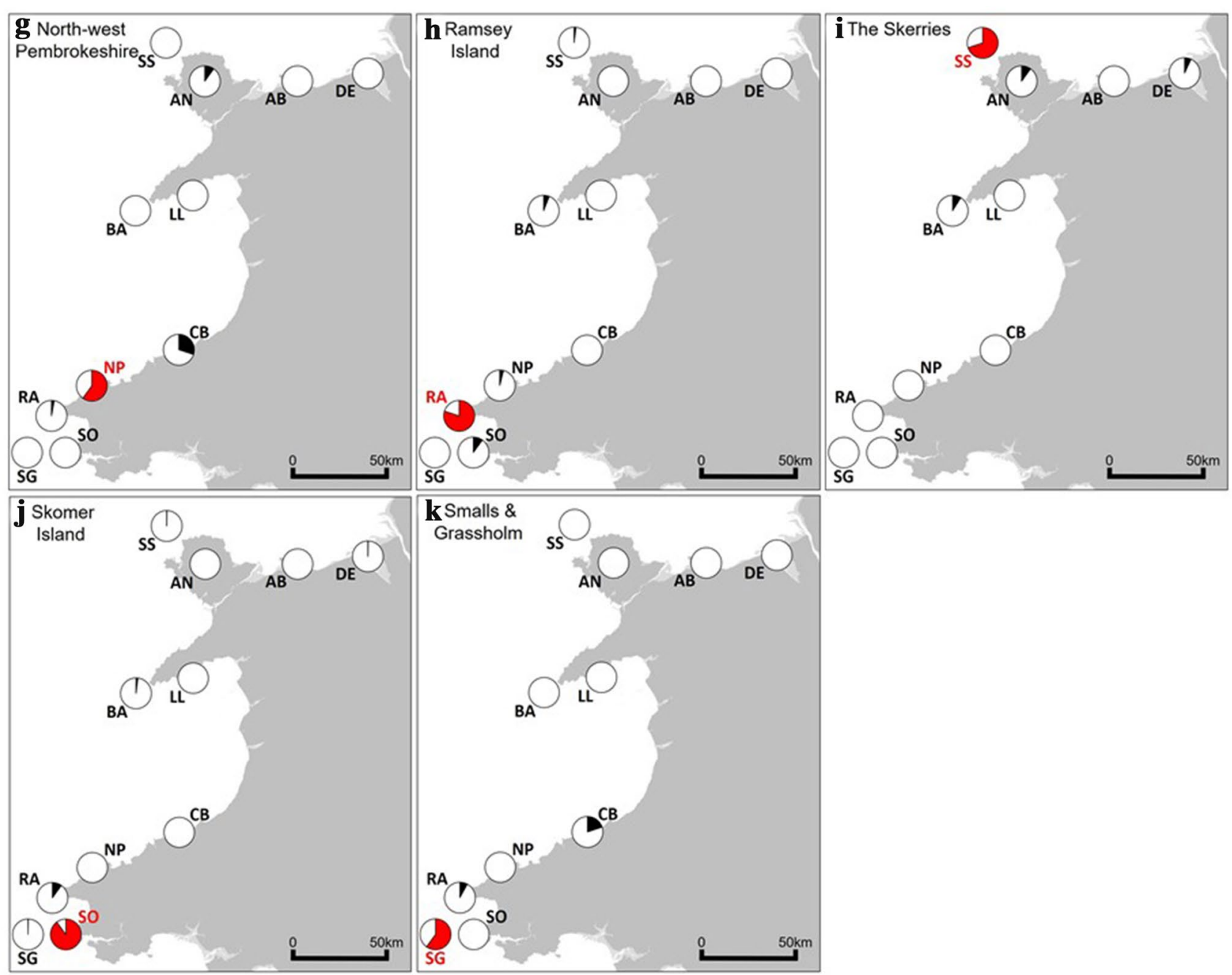

Fig. 5 (continued)

Anglesey $(n=3)$ and the Skerries $(n=2)$. Breeding season seals at Ramsey were detected outside of the breeding season at Ramsey $(n=3)$ and Skomer $(n=1)$. Seals detected during the breeding season at Skomer were only ever recaptured outside the season within Skomer $(n=2)$.

\section{Discussion}

Obtaining an estimate of grey seal abundance and understanding the spatial connectivity between grey seal haulout sites are important for effective conservation management. A minimum of 2,688 individual adult female grey seals used haul-out sites around the Welsh coastline between 1992 and 2016. It is not surprising that this total is greater than the latest estimate for annual pup production in Wales ( $n=1650$; Duck and Morris 2016). Even if the "Welsh" grey seals represent a closed population in demographic terms, the extended time series of observations will result in a turnover of individuals due to mortality and births. The early peak in surveying effort in 1997 identified 229 seals in Wales and Ireland, but by the 2006 surveys, only 132 of these would be expected to be alive. Of the 229 seals from 1997, 132 seals were seen first in Wales and 76 would still be expected to be alive in 2006; EIRPHOT contains resightings of 9 of these from 2006 onwards (see Supplementary Material 2, Table S6).

We found evidence of connectivity; between sites up to $230 \mathrm{~km}$ apart along the Welsh coast, within special areas for conservation (SACs), between different SACs, and between SACs and non-designated areas. These results demonstrate the spatial and temporal scales of site use by a highly mobile marine predator and the need to consider both these scales for management, monitoring, and environmental assessments. 

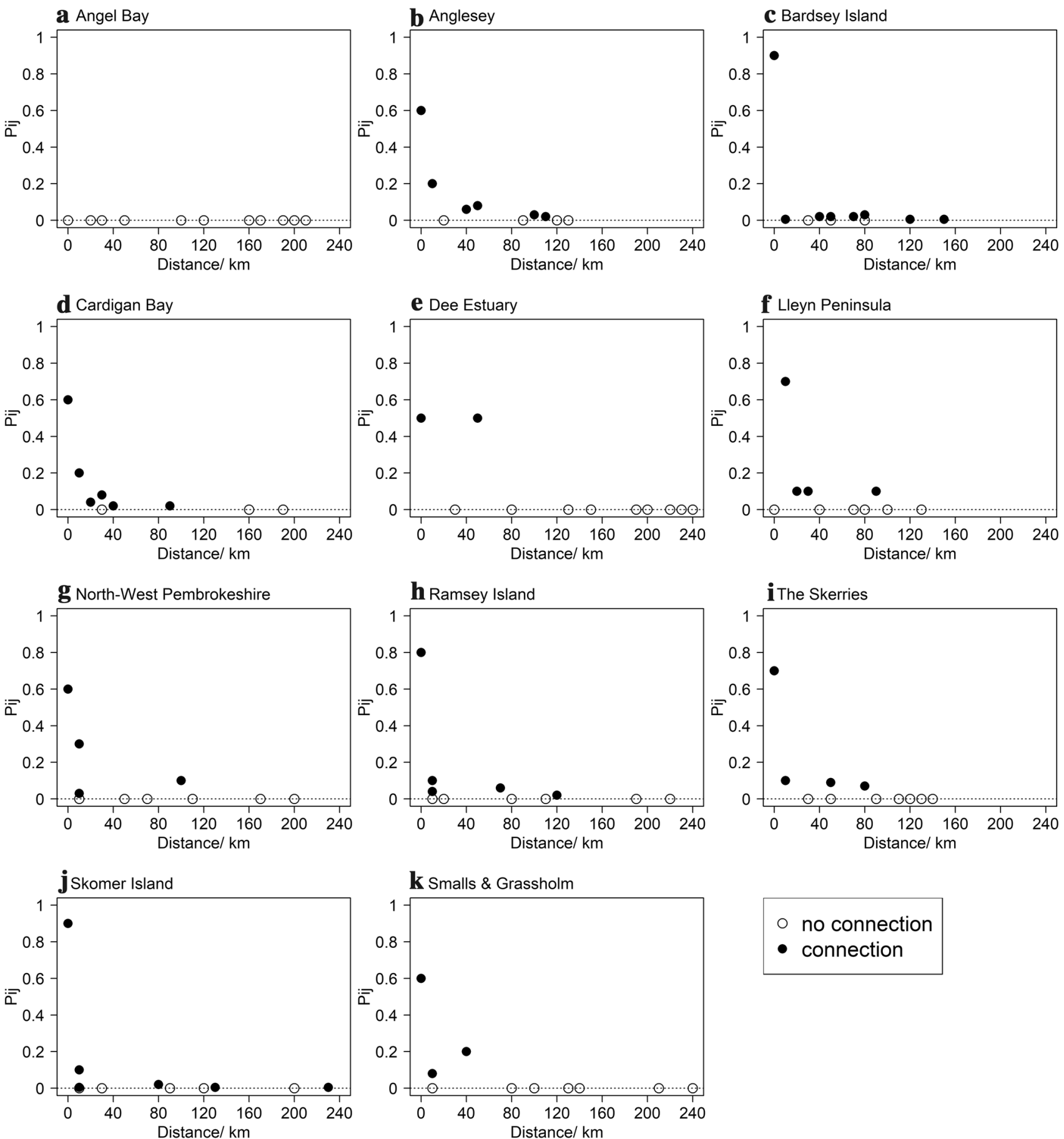

Fig. 6 Relative spatial transition probabilities $\left(P_{i j}\right)$ by distance to the nearest $10 \mathrm{~km}$ between capture $(i)$ and recapture $(j)$ location groups. Both connected haul-out sites and haul-out sites not connected through photographic identification are presented

\section{Spatial connectivity of sites used between years}

In our study, the greatest distance between two haul-out locations was $240 \mathrm{~km}$, and the greatest distance between photo-ID recaptures (Rdist) was $230 \mathrm{~km}$, coincidentally similar to Sayer et al. (2019) and well within the known range of individuals of the species (McConnell et al. 1999). It is still not fully understood why grey seals choose to haul-out at some sites over others, although habitat suitability and lack of disturbance are likely to be important. However, the variation in size and physical features 
Table 2 Recapture frequency of site fidelity during the breeding season (beginning of August to end of November) over consecutive, location specific 4-year periods, shaded by spatial transition probability $\left(P_{i j}\right)$

\begin{tabular}{|l|c|c|c|c|c|}
\hline \multirow{2}{*}{$\begin{array}{l}\text { Breeding season } \\
\text { capture location group }\end{array}$} & \multicolumn{5}{|c|}{ Recapture location group } \\
\cline { 2 - 6 } & SS & BA & RA & SO & AN \\
\hline Skerries (SS) & 18 & 1 & & & 3 \\
\hline Bardsey (BA) & 1 & 105 & & 2 & \\
\hline Ramsey (RA) & & & 32 & & \\
\hline Skomer (SO) & & 5 & 7 & 94 & \\
\hline
\end{tabular}

\begin{tabular}{|c|c|}
\hline & \multicolumn{1}{|c|}{$P_{i j}=0$} \\
\hline & $0<P_{i j}<0.2$ \\
\hline & $0.2 \leq P_{i j}<0.4$ \\
\hline & $0.4 \leq P_{i j}<0.6$ \\
\hline & $0.6 \leq P_{i j}<0.8$ \\
\hline & $0.8 \leq P_{i j} \leq 1$ \\
\hline
\end{tabular}

AN (Anglesey) is not a breeding site but it did occur in the data as a recapture location

Table 3 Capture histories showing spatial connectivity between breeding areas for individuals recorded in the breeding season (Aug-Nov; in grey) and at least once outside of the breeding season (Dec-Jul)

\begin{tabular}{|c|c|c|c|c|c|c|c|c|c|c|c|c|c|c|}
\hline \multirow{2}{*}{ Site } & \multirow{2}{*}{ Year } & \multirow{2}{*}{$n$} & \multicolumn{12}{|c|}{ Month } \\
\hline & & & Jan & Feb & Mar & Apr & May & Jun & Jul & Aug & Sep & Oct & Nov & Dec \\
\hline \multirow{9}{*}{ 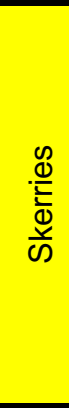 } & \multirow{2}{*}{2009} & 2 & AN & & & & & & & & & SS & & \\
\hline & & 1 & & AN & & & & & & & & SS & & \\
\hline & \multirow{4}{*}{2010} & 2 & & & & & & & & & & & SS & SS \\
\hline & & 1 & SS & & & & & & & & & & SS & \\
\hline & & 1 & SS & & & & & & & & & SS & & \\
\hline & & 1 & & & & & & AN & & & & & SS & $\mathrm{BA}$ \\
\hline & 2011 & 1 & & & $\mathrm{BA}$ & & & & & & & & SS & \\
\hline & \multirow{2}{*}{2012} & 1 & & & & & & & SS & & & & SS & \\
\hline & & 1 & & & & & & & SS & SS & & & & \\
\hline \multirow{14}{*}{ 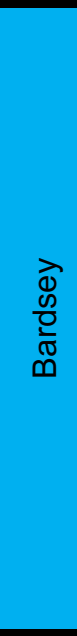 } & 2008 & 0 & & & & & & & & & & & & \\
\hline & \multirow{3}{*}{2009} & 1 & & & AN & & & & & & & $\mathrm{BA}$ & & \\
\hline & & 1 & & AN & & & & & & & & BA & & \\
\hline & & 1 & & AN & & & & & & & $\mathrm{BA}$ & $\mathrm{BA}$ & & \\
\hline & \multirow{6}{*}{2010} & 4 & & & & & & & & & $\mathrm{BA}$ & & & $\mathrm{BA}$ \\
\hline & & 3 & & & & & & & & & $\mathrm{BA}$ & BA & & BA \\
\hline & & 1 & & BA & & & & & & & $B A$ & & & \\
\hline & & 1 & SS & & & & & & & & & $\mathrm{BA}$ & & \\
\hline & & 1 & SS & & & & & & & & $\mathrm{BA}$ & $\mathrm{BA}$ & & \\
\hline & & 1 & & & & & & & & & $\mathrm{BA}$ & & $\mathrm{BA}$ & $\mathrm{BA}$ \\
\hline & \multirow{4}{*}{2011} & 1 & & & & & $\mathrm{BA}$ & & & $\mathrm{BA}$ & & & & \\
\hline & & 1 & & & & & & $\mathrm{BA}$ & & & $\mathrm{BA}$ & & & \\
\hline & & 1 & & & $B A$ & & & & & & & & $\mathrm{BA}$ & \\
\hline & & 1 & & BA & & & $\mathrm{BA}$ & & & & $\mathrm{BA}$ & & & \\
\hline \multirow{6}{*}{ 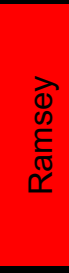 } & \multirow{3}{*}{2013} & 1 & RA & & & & & & & & & RA & & \\
\hline & & 1 & & & & SO & & & & & & $\mathrm{RA}$ & & \\
\hline & & 1 & 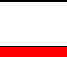 & & & & & & & $\mathrm{RA}$ & & & & $\mathrm{RA}$ \\
\hline & 2014 & 1 & $\mathrm{RA}$ & & $\mathrm{RA}$ & & & & & & $\mathrm{RA}$ & & & $\mathrm{RA}$ \\
\hline & 2015 & 0 & & & & & & & & & & & & \\
\hline & 2016 & 0 & & & & & & & & & & & & \\
\hline \multirow{4}{*}{ 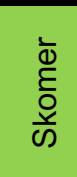 } & 2008 & 1 & & & & & & & SO & & SO & & & \\
\hline & 2009 & 1 & & & & & so & & & & so & & & \\
\hline & 2010 & 0 & & & & & & & & & & & & \\
\hline & 2011 & 0 & & & & & & & & & & & & \\
\hline
\end{tabular}

Multiple seals sometimes had the same capture histories (n). Location groups are colour coordinated for presentation purposes 
in known pupping sites (Baines et al. 1995) implies that many factors contribute to site use (Russell et al. 2017).

We found that seals first recorded at Bardsey were subsequently recaptured at sites to the north and to the south of the island. However, connectivity to the adjacent Lleyn Peninsula $(<10 \mathrm{~km}$ away) was low $(n=43)$. It is possible that comparatively lower effort at the Lleyn Peninsula contributed to this result as throughout the years, there were only 250 images recorded in the database from the Lleyn Peninsula, compared to over a thousand images included from Anglesey $(n=1212)$, Bardsey $(n=3904)$, Ramsey $(n=1199)$, the Skerries $(n=1364)$ and Skomer $(n=2164$; see Supplementary Material 1, Fig. S1). Sites on the Lleyn Peninsula have not been surveyed as consistently through the years, whereas Bardsey, Ramsey and Skomer are all prominent breeding areas and much of the effort has been focussed historically on breeding seasons (Baines et al. 1995; Stringell et al. 2014). However, the relative spatial transition probability of seals from the Lleyn Peninsula to Bardsey Island was high, suggesting that Bardsey Island is a well-used site in this region.

Seals seen in Cardigan Bay had a predominantly southerly exchange to NW Pembrokeshire (the closest location group at $\leq 10 \mathrm{~km}$ away), but were also connected to island and mainland sites in North and Southwest Wales.

\section{Breeding site fidelity across years}

In this analysis, we used data from the month of August-November to encompass the breeding season, which covers $95 \%$ of pup production at the main colonies (Westcott 2002; Büche and Stubbings 2019). However, across Wales, individual female grey seals have been recorded with a pup in July and December (Baines et al. 1995; Westcott and Stringell 2003; Büche and Stubbings 2019) and throughout the year at Ramsey (Morgan et al. 2018). Elsewhere, individual pupping dates tend to be conserved around the colony mean (Pomeroy et al. 1994) so while our breeding analysis would exclude such individuals consistently, they might be photographed outside the breeding season. We found no connectivity between Ramsey Island with other monitored sites during the breeding season, suggesting especially high breeding site fidelity here. There have been reported resights of grey seals between Ramsey Island and Cornwall (Sayer et al. 2019), but the time of year, sex and pupping status of the individuals were not available to include in this analysis.

We did find connectivity between the other three main breeding locations in this study. There were connections between Bardsey Island and the Skerries in North Wales, and with Skomer Island in Southwest Wales. It is perhaps surprising that during a time of year when capital breeders are foraging less (Stearns 1989), adult females are nevertheless travelling around much of the Welsh coastline.
Similarly, seals first detected at Skomer Island during the breeding season were subsequently recaptured at Bardsey Island within the same 4-month period. Our definition of the breeding season may explain some of these resightings: individual mothers only spend around 20 days raising their offspring during the breeding season which can span 8-10 weeks at each colony (Duck and Morris 2016). Without detailed pupping status information at all locations where the individuals were seen, it is difficult to assign definite breeding locations to animals, but we assumed that the first recorded location during this breeding season was the breeding location. Whilst our analysis would be improved with site-specific pupping status of females, photo-ID surveys are not always able to ascertain this due to the limited time available to observe each individual seal and the surveyor's experience.

For the Skerries, the highest connectivity during the breeding season was with Anglesey, a site not known to be used by breeding grey seals. Due to the absence of pupping records for some locations, the connectivity of grey seal sites within the breeding season in this study may include nonbreeding females-either pre-breeders or individuals "on sabbatical" from breeding, as seen in Weddell seal populations in Antarctica (Chambert et al. 2015).

\section{Spatial connectivity of breeding and non-breeding areas within years}

In North Wales, individuals recorded during the breeding season at Bardsey Island and the Skerries were recorded outside of the breeding season at other locations in North Wales. In Southwest Wales, individuals recorded during the breeding season at Ramsey Island were recorded at Skomer earlier in the year. Individual variability is often seen in grey seal behaviour (e.g. McConnell et al. 1999), so the fact that multiple individuals had similar capture histories is of interest (e.g. those individuals recorded in the Skerries during the breeding season use Anglesey earlier in the year). These results provide insight into grey seal site use over a 12-month period, which is not possible through telemetry studies where tags are designed to fall off during the annual moult.

The implications of these results are relevant to marine spatial planning and to the conservation of protected species. Grey seals are protected under national (The UK Conservation of Seals Act 1970) and international (EU Habitats Directive) legislation, and so anthropogenic activities need to consider both breeding sites during the breeding season and connected sites outside of the breeding season. For example, breeding seals in the Skerries could be affected by activities around Anglesey and Bardsey Island earlier in the year. Moreover, given the demonstrated connectivity among breeding and non-breeding sites around Wales and beyond, 
a marine industrial development at one location within the study area would need to consider their effects on seals at sites elsewhere in the wider area. Our data support the need to consider connectivity of seal sites in environmental assessments such as Environmental Impact Assessments (EIAs) and Habitats Regulations Assessments (HRAs) and provide credible evidence in support of the concept of functionally linked land (or sea) in marine planning (Chapman and Tyldesley 2016).

\section{EIRPHOT database}

Long-term datasets resulting from monitoring programmes are subject to changes in resources through time, particularly staffing and available funding, as well as the unpredictable effects of weather conditions on opportunities for collecting photographic images. Consequently, formal capture-mark-recapture analysis assumptions cannot be satisfied. Here, we overcame variation in monitoring effort by reporting the relative proportion of recaptures between location groups which allows connectivity between haul-out sites to be investigated. However, over the decades, effort has been biased by location (haul-out sites with dedicated reserve wardens such as Bardsey, Ramsey and Skomer Islands providing large datasets) and season (more data, at more frequent intervals, have been collected during the pupping season, in places where large numbers of grey seals haul-out, and alongside other studies with a breeding focus).

In the EIRPHOT database, around $60 \%$ of identified seals have originated from the islands of Bardsey, Ramsey and Skomer. Angel Bay, first documented in Westcott and Stringell (2003), had the fewest photo-ID surveys included in the database. However, since 2017, formal photo-ID surveys have been carried out at Angel Bay with numbers now exceeding 200 hauled-out during the moult and 2-3 pups born a year (pers. comms. The North Wales Wildlife Trust) but these data have yet to be included in EIRPHOT. This site is clearly becoming important for grey seals in North Wales and warrants further investigation. This study provides an overview of what the EIRPHOT database currently represents but doesn't represent the full extent of available data. Future research would benefit from the addition of outstanding datasets along with further surveys based on a consistent, structured and more comprehensive protocol for photo-ID, with wider training in the use of the EC software. This standardisation would enable wider collaborations to be made around Wales and beyond.

The high proportion of individuals identified that were seen only once $(83 \%)$ has a number of potential explanations (Hiby et al. 2013). First, there is the availability of an animal to be resighted which will depend on death, emigration, or becoming otherwise unavailable to being photographed after their initial capture. Having once taken the photographs, there is a risk of missing matches between images of the same part of a seal, but we have minimised this by setting the EC pattern comparison threshold to 0.75 , forcing more candidate matches to be visually examined. In reality, a combination of these explanations is likely. The variability of sampling effort makes it difficult to determine the relative likelihood of each, but further analyses are possible.

The EIRPHOT database is not limited to grey seal haulout sites in Wales and includes photo-ID data from the east and west coasts of Ireland, the southwest coast of England, the Isle of Man and the north coast of France (see Supplementary Material 1, Fig. S1). Telemetry studies have shown that grey seals in the Celtic and Irish Seas move between Wales, Ireland, England and France (Cronin 2011; Cronin et al. 2016; Carter et al. 2017; Russell et al. 2017; Vincent et al. 2017) and photo-ID studies have also shown a connection between Wales and Ireland (Kiely et al. 2000) and Wales and Cornwall (Sayer et al. 2019). The Isles of Scilly off the west coast of Cornwall are also a key node for grey seals in Southwest Wales (Vincent et al. 2016; Russell et al. 2017). There are limited studies looking at the movement of grey seals between Wales and the Isle of Man specifically, but UK grey seal usage maps generated from telemetry data (Russell et al. 2017) show that the south coast of the Isle of Man provides suitable habitat and haul-out locations for grey seals in North Wales. Continuing collaborations between groups collecting data on grey seals are paramount to furthering our understanding of the ecology of this protected species.

\section{Conclusions}

Adult grey seals found within Welsh SACs range over the wider Celtic and Irish Seas. Although they show breeding site fidelity, at other times of year, seals are not limited to the sites at which they breed, and haul-outs at least $230 \mathrm{~km}$ apart were used by the same individuals. While telemetry studies provide real-time movement of grey seals at-sea, along with information on activity budgets (Russell et al. 2015), foraging behaviour (Thompson et al. 1991; McConnell et al. 1999; Vincent et al. 2016; Carter et al. 2017) and interactions with anthropogenic activities (Hastie et al. 2015; Cronin et al. 2016), they are expensive and require capture and handling of relatively few subjects. Long-term photo-ID studies are a cost-effective method which can contribute to the understanding of the complex site use and connectivity of seals. As grey seals from SACs rely on sites outside those protected areas, conservation management should consider potential impacts beyond site boundaries to fully reflect the highly mobile, wide ranging nature of this species. 
Acknowledgements EIRPHOT was established with funding from the Irish Government through its National Parks and Wildlife Service, Department of the Marine and Natural Resources and Bord lascaigh Mhara. After its expansion into Wales under the EU's INTERREG Programme, The Countryside Council for Wales/Natural Resources Wales (CCW/NRW) supported ongoing work from 2003 via contracts to LH and PP. The UK Natural Environment Research Council (NERC) provided core funding to the Sea Mammal Research Unit (NERC Grant No. NE/G008930/1) and The Esmée Fairbairn Foundation provided additional funding to PP and LH to extend photo-ID for grey seals. The authors thank all those who contributed voluntarily and professionally in collaborations over the duration of the work. We are very grateful to all those involved during early development and populating of the EIRPHOT database in Wales, Ireland and beyond. This includes staff and contractors of CCW/NRW, and the many other contributors and organisations that helped. We would also like to thank the two anonymous reviewers whose comments helped to improve this manuscript. The work is dedicated to Mandy McMath (late of CCW), whose enthusiasm, drive and belief enabled this study.

Funding The UK Natural Environment Research Council (NERC) provided core funding to the Sea Mammal Research Unit during this work and NERC Grant No. NE/G008930/1 to PP and LH to develop photo-ID use for grey seals. The Esmée Fairbairn Foundation provided additional funding to PP and LH for photo-ID work with grey seals. NRW funded survey work by MB, LM, SW and PS; contracted LH for survey design, software development and data management; IL and PP for work related to the production of this manuscript.

Data availability The dataset is available under the terms of the Open Government Licence and is freely available to download from the Lle Geoportal: https://lle.gov.wales/catalogue/item/EIRPHOT/

\section{Compliance with ethical standards}

Conflict of interest The authors declare that they have no conflicts of interest.

Ethical approval No animals were handled during this work. Survey work supervised by NRW was carried out with reference to ASAB guidelines or had approval of University of St Andrews Animal Welfare and Ethics Committee as appropriate.

Open Access This article is licensed under a Creative Commons Attribution 4.0 International License, which permits use, sharing, adaptation, distribution and reproduction in any medium or format, as long as you give appropriate credit to the original author(s) and the source, provide a link to the Creative Commons licence, and indicate if changes were made. The images or other third party material in this article are included in the article's Creative Commons licence, unless indicated otherwise in a credit line to the material. If material is not included in the article's Creative Commons licence and your intended use is not permitted by statutory regulation or exceeds the permitted use, you will need to obtain permission directly from the copyright holder. To view a copy of this licence, visit http://creativecommons.org/licenses/by/4.0/.

\section{References}

Baines ME, Earl SJ, Pierpoint CJL, Poole J (1995) The West Wales grey seal census. Countryside Council for Wales Contract Science Report 131:240. Countryside Council for Wales, Bangor.
Boyd IL, Wanless S, Camphuysen CJ (2006) Top predators in marine ecosystems: their role in monitoring and management. Cambridge University Press, Cambridge

Büche B, Stubbings E (2019) Grey Seal Breeding Census, Skomer Island 2018. NRW Evidence Report 325. The Wildlife Trust of South and West Wales

Carter MI, Russell DJ, Embling CB, Blight CJ, Thompson D, Hosegood PJ, Bennett KA (2017) Intrinsic and extrinsic factors drive ontogeny of early-life at-sea behaviour in a marine top predator. Sci Rep 7(1):15505. https://doi.org/10.1038/s41598-017-15859-8

Chambert T, Rotella JJ, Garrott RA (2015) Female Weddell seals show flexible strategies of colony attendance related to varying environmental conditions. Ecology 96:479-488. https://doi. org/10.1890/14-0911.1

Chapman C, Tyldesley D (2016) Functional linkage: how areas that are functionally linked to European sites have been considered when they may be affected by plans and projects-a review of authoritative decisions. Natural England Commissioned Report 207.

Critchley EJ, Grecian WJ, Kane A, Jessopp MJ, Quinn JL (2018) Marine protected areas show low overlap with projected distributions of seabird populations in Britain and Ireland. Biol Cons 224:309-317. https://doi.org/10.1016/j.biocon.2018.06.007

Cronin MA (2011) The conservation of seals in Irish waters: how research informs policy. Marine Policy 35(6):748-755. https:// doi.org/10.1016/j.marpol.2011.01.006

Cronin M, Gerritsen H, Reid D, Jessopp M (2016) Spatial overlap of grey seals and fisheries in Irish waters some new insights using telemetry technology and VMS. PLoS ONE 11(9):e0160564. https://doi.org/10.1371/journal.pone.0160564

Donovan GP, Hammond PS, Mizroch SA (1990) Individual recognition of cetaceans: Use of photo-identification and other techniques to estimate population parameters: incorporating the proceedings of the Symposium and Workshop on Individual Recognition and the Estimation of Cetacean Population Parameters. International Whaling Commission, Cambridge

Duck CD, Morris CD (2018) Grey seal pup production in Britain in 2016. SCOS Briefing Paper 18/01, Scientific Advice on Matters Related to the Management of Seal Populations. Sea Mammal Research Unit, St Andrews

Fedak MA, Anderson SS (1982) The energetics of lactation: accurate measurements from a large wild mammal the grey seal (Halichoerus grypus). J Zool 198(4):473-479. https://doi.org/10.1111/ jzo.1982.198.4.473

Hastie GD, Russell DJ, McConnell B, Moss S, Thompson D, Janik VM (2015) Sound exposure in harbour seals during the installation of an offshore wind farm: predictions of auditory damage. J Appl Ecol 52:631-640. https://doi.org/10.1111/1365-2664.12403

Hiby AR, Lovell P (1990) Computer aided matching of natural marks: A prototype system for grey seals. International Whaling Commission Report: Special Issue 12:57-62. International Whaling Commission, Cambridge

Hiby L, Paterson W, Redman R, Watkins J, Twiss SD, Pomeroy P (2013) Analysis of photo-id data allowing for missed matches and individuals identified from opposite sides. Methods Ecol Evol 4(3):252-259. https://doi.org/10.1111/2041-210x.12008

Jain AK (2007) Technology: biometric recognition. Nature 449(7158):38-40. https://doi.org/10.1038/449038a

Kiely O, Lidgard DC, McKibben M, Connolly N, Baines ME (2000) Grey seals: status and monitoring in the Irish and Celtic Seas. Maritime Ireland/Wales INTERREG Report 3. Marine Institute, Dublin

Langley I, Rosas da Costa Oliver T, Hiby L, Morris CW, Stringell TB, Pomeroy P (2018) EIRPHOT: a critical assessment of Wales' grey seal (Halichoerus grypus) photo-identification database. NRW Evidence Report 280:94. Natural Resources Wales, Bangor 
McConnell BJ, Fedak MA, Lovell P, Hammond PS (1999) Movements and foraging areas of grey seals in the North Sea. J Appl Ecol 36(4):573-590. https://doi.org/10.1046/j.1365-2664.1999.00429.x

Morgan LH, Morris CW, Stringell TB (2018) Grey seal pupping phenology on Ynys Dewi/Ramsey Island, Pembrokeshire. NRW Evidence Report 156:22. Natural Resources Wales, Bangor

Paterson WD, Redman P, Hiby LA, Moss SE, Hall AJ, Pomeroy P (2013) Pup to adult photo-ID: evidence of pelage stability in gray seals. Mar Mamm Sci 29(4):537-541. https://doi.org/10.1111/ mms. 12043

Pianka ER (1970) On r-and K-selection. Am Nat 104(940):592-597. https://doi.org/10.1086/282697

Pomeroy PP, Anderson SS, Twiss SD, McConnell BJ (1994) Dispersion and site fidelity of breeding female grey seals (Halichoerus grypus) on North Rona Scotland. J Zool 233(3):429-447. https:// doi.org/10.1111/j.1469-7998.1994.tb05275.x

Pomeroy PP, Fedak MA, Rothery P, Anderson S (1999) Consequences of maternal size for reproductive expenditure and pupping success of grey seals at North Rona Scotland. J Anim Ecol 68(2):235-253. https://doi.org/10.1046/j.1365-2656.1999.00281.x

Pomeroy PP, Twiss SD, Redman P (2000) Philopatry, site fidelity and local kin associations within grey seal breeding colonies. Ethology 106(10):899-919. https://doi.org/10.104 6/j.1439-0310.2000.00610.x

Russell DJF, McConnell B, Thompson D, Duck C, Morris C, Harwood J, Matthiopoulos J (2013) Uncovering the links between foraging and breeding regions in a highly mobile mammal. J Appl Ecol 50:499-509. https://doi.org/10.1111/1365-2664.12048

Russell DJF, McClintock BT, Matthiopoulos J, Thompson PM, Thompson D, Hammond PS, Jones EL, MacKenzie ML, Moss S, McConnell BJ (2015) Intrinsic and extrinsic drivers of activity budgets in sympatric grey and harbour seals. Oikos 124:1462-1472. https ://doi.org/10.1111/oik.01810

Russell DJF, Jones EL, Morris CD (2017) Updated seal usage maps: the estimated at-sea distribution of grey and harbour seals. Scott Mar Freshw Sci 8(25):2027-2031. https://doi.org/10.7489/2027-1

Sayer S, Allen R, Hawkes LA, Hockley K, Jarvis D, Witt MJ (2019) Pinnipeds, people and photo identification: the implications of grey seal movements for effective management of the species. J Mar Biol Assoc UK. https://doi.org/10.1017/S0025315418001170

Smout S, King R, Pomeroy P (2011) Estimating demographic parameters for capture-recapture data in the presence of multiple mark types. Environ Ecol Stat 18(2):331-347. https://doi.org/10.1007/ s10651-010-0135-y

Sparling CE, Fedak MA, Thompson D (2007) Eat now, pay later? Evidence of deferred food-processing costs in diving seals. Biol Let 3(1):95-99. https://doi.org/10.1098/rsbl.2006.0566
Special Committee on Seals; SCOS (2018) Scientific advice on matters related to the management of seal populations. Sea Mammal Research Unit, St Andrews

Stearns SC (1989) Trade-offs in life-history evolution. Funct Ecol 3(3):259-268. https://doi.org/10.2307/2389364

Stringell TB, Millar CP, Sanderson WG, Westcott SM, McMath MJ (2014) When aerial surveys will not do: grey seal pup production in cryptic habitats of Wales. J Mar Biol Assoc UK 94(6):11551159. https://doi.org/10.1017/S0025315413000064

Thomas L, Russell DJ, Duck CD, Morris CD, Lonergan M, Empacher F, Thompson D, Harwood J (2019) Modelling the population size and dynamics of the British grey seal. Aquat Conserv Mar Freshw Ecosyst 29:6-23. https://doi.org/10.1002/aqc.3134

Thompson D, Hammond PS, Nicholas KS, Fedak MA (1991) Movements, diving and foraging behaviour of grey seals (Halichoerus grypus). J Zool 224:223-232. https://doi. org/10.1111/j.1469-7998.1991.tb04801.x

Vincent C, Meynier L, Ridoux V (2001) Photo-identification in grey seals: legibility and stability of natural markings. Mammalia 65(3):363-372. https://doi.org/10.1515/mamm.2001.65.3.363

Vincent C, Ridoux V, Fedak MA, McConnell BJ, Sparling CS, Leaute JP, Joumaa J, Spitz J (2016) Foraging behaviour and prey consumption by grey seals (Halichoerus grypus) — spatial and trophic overlaps with fisheries in a marine protected area. ICES J Mar Sci 73(10):2653-2665. https://doi.org/10.1093/icesjms/fsw102

Vincent C, Huon M, Caurant F, Dabin W, Deniau A, Dixneuf S, Dupuis L, Elder JF, Fremau MH, Hassani S, Hemon A, Karpouzopoulos J, Lefeuvre C, McConnell BJ, Moss SEW, Provost P, Spitz J, Turpin Y, Ridoux V (2017) Grey and harbour seals in France: Distribution at sea, connectivity and trends in abundance at haulout sites. Deep Sea Res Part II 141:294-305. https://doi.org/10.1016/j. dsr2.2017.04.004

Westcott SM (2002) The distribution of grey seals (Halichoerus grypus) and census of pup production in North Wales, 2001. CCW Contract Science Report 499:150. Countryside Council for Wales, Bangor

Westcott SM, Stringell TB (2003) Grey seal pup production for North Wales, 2002. CCW Marine Monitoring Report 5:57. Countryside Council for Wales, Bangor

Publisher's Note Springer Nature remains neutral with regard to jurisdictional claims in published maps and institutional affiliations. 